\title{
Gastroenterology, hepatology, and nutrition
}

\section{G14 COMPARISON OF THE EFFECT OF AN OLIVE OIL (CLINOLEIC) AND A SOYA BASED LIPID EMULSION (INTRALIPID) ON PULMONARY HAEMODYNAMICS IN PRETERM INFANTS-RESULTS OF PILOT STUDY}

L.S. Miall', J.W.L. Puntis', D. Thompson'2. 'Neonatal Intensive Care Unit, ${ }^{2}$ Department of Chemical Pathology, Leeds Teaching Hospitals NHS Trust, Leeds, UK

Rationale: Soya based lipid emulsions increase pulmonary pressure in preterm infants. This is thought to be due to production of vasoactive prostaglandins from fatty acids. Emulsions based on olive oil contain less poly-unsaturated fatty acids and may have less effect on pulmonary haemodynamics.

Method: A non-invasive estimate of pulmonary pressure (time to peak velocity/right ventricular ejection time (TPV/RVET)) was performed using echocardiography in preterm infants. Each subject received increasing doses $(0 \mathrm{to} 3 \mathrm{~g} / \mathrm{kg} /$ day) of either Intralipid or Clinoleic over the first week of life. TPV/RVET was measured at baseline and at maximum dose in each infant. Prostaglandin metabolites thromboxane B2 and 6-keto PGF $1 \alpha$ were measured in urine.

Results: 15 infants were studied. 10 received Intralipid and $5 \mathrm{Cli}$ noleic. TPV/RVET increased in both groups with time. (reflecting a fall in pulmonary pressure) The percentage change on TPV/RVET was greater in the group receiving Clinoleic ( $83.4 \%$ v $12.1 \%)$. The ratio of thromboxane B2 to 6-keto PGF $1 \alpha$ fell in the Clinoleic group.

Conclusions: This pilot study suggests that olive oil based lipid emulsions may have less effect on pulmonary haemodynamics than soya based emulsions in preterm infants receiving intensive care, and that this may be mediated by altered prostaglandin production.

\section{G15 EFFECT OF HIGH CALORIC DIET ON NUTRITIONAL PARAMETERS OF CHILDREN WITH THALASSAEMIA MAJOR}

W. El-Matary, A.T. Soliman, M.A. Fattah, I. Nasr', R.E. Alaily. Departments of Paediatrics and 'Clinical Pathology, Faculty of Medicine, University of Alexandria, Egypt

Introduction: Impaired growth accompanying thalassaemia major poses diagnostic and therapeutic problems.

Aim: To test the hypothesis that impaired growth might be corrected, partially or totally, by increasing caloric intake of these patients to compensate for their hypermetabolic status accompanying their anemia and bone marrow hyperactivity.

Material and Methods: Thirty randomly selected children with thalassaemia major were studied. The dietary intake of the thalassaemic patients, was evaluated by the recall method, appeared to be adequate compared to 30 normal age-matched children. Nutritional status was assessed by measuring the weight, body mass index (BMI), mid-arm circumference (MAC), triceps skin fold thicknesss (SFT) and serum albumin and insulin-like growth factor-I (IGF-I) concentrations before and after 8 weeks of high-caloric diet (130-150\% of the caloric recommendation for age and sex).

Results: BMI, triceps SFT and MAC of children with thalassaemia were significantly decreased compared to those for the normal control group. IGF-I and albumin concentrations in thalassemic children $(69+/-20.5 \mathrm{ng} / \mathrm{m}$ and $3.65+/-0.67 \mathrm{~g} / \mathrm{dl}$ respectively) were significantly lower than in normal age-matched children (162.5 +/- 24 $\mathrm{ng} / \mathrm{ml}$ and $4.29+/-0.66 \mathrm{~g} / \mathrm{dl}$ respectively). After nutritional supplementation for 8 weeks the MAC, SFT and BMI of the thalassaemic children increased significantly $(p<0.05)$. Serum IGF-I $(84.3+/-27.3$ $\mathrm{ng} / \mathrm{ml})$ and albumin concentrations $(3.85+/-0.85 \mathrm{~g} / \mathrm{dl})$ increased significantly in the thalassaemic group after versus before nutritional supplementation, however, they were still lower than those of normal children.

Conclusion: Hypermetabolic status of thalassaemic children contributes to their low IGF-I levels with subsequent slowing of linear growth and weight gain. Increased caloric dietary intake increased significantly IGF-l levels, and improved growth.

\section{G16 DETERMINANTS OF ANNUAL CHANGE IN LUMBAR SPINE AND TOTAL BODY BONE SIZE AND MASS IN CHILDREN WITH CYSTIC FIBROSIS}

Y.Y. Chan, C.J. Taylor, N.J. Bishop. Child Health, University of Sheffield, Sheffield Children's Hospital, Sheffield, UK

Young adults with Cystic Fibrosis (CF) have an increased risk of osteopenia and fracture. Cross-sectional studies demonstrated the multifactorial nature of CF bone disease, however factors influencing bone mass accrual in CF is still lacking.

Objective: To identify predictors of change in bone mass in children with CF.

Methods: One-year prospective review on $83 \mathrm{CF}$ children aged 5-18 years of their annual lumbar spine and total body bone area and mass which determined by Dual-energy $x$ ray Absorptiometry. Using multiple linear regression, prediction models for change in lumbar spine and total body bone area and mass were created with nutritional, respiratory and liver disease status, dietary intakes, steroid therapy and physical activity data as independent variables.

Results: The factors which in combination most strongly predicted changes in lumbar spine bone area (adjusted $R^{2}=57 \%$ ) and mass (adjusted $\mathrm{R}^{2}=67 \%$ ) were changes in lean mass, body height, Shwachman chest $x$ ray score, female gender (all positive) and change in serum alkaline phosphatase and averaged steroid dosage (both negative). The factors which in combination most strongly predicted changes in total body bone area (adjusted $R^{2}=67 \%$ ) and mass (adjusted $R^{2}=71 \%$ ) were changes in lean mass, fat mass, body height, female gender (all positive), and change in scapular skinfoldthickness and serum alkaline phosphatase (both negative). We found no additional independent effect of lung functions, dietary calcium, physical activity and liver disease on change in lumbar spine and total body bone mass in CF.

Conclusions: The major determinants of annual change in lumbar spine and total body bone mass in children with CF are changes in lean tissue, fat mass and body height. These results suggest measures to optimise CF bone mass accrual by improving nutritional status, minimising steroid dose and reducing radiological structural lung changes through effective prevention and treatment of chest infections.

\section{G17 THE LONG TERM EFFECT OF BREAST FEEDING: COGNITIVE FUNCTION IN THE CAERPHILLY COHORT}

P.C. Elwood', J. Pickering', D.P. Davies², J.E.J. Gallagher'. Departments of 'Epidemiology, Statistics and Public Health, and ${ }^{2}$ Child Health, University of Wales College of Medicine Heath Park Cardiff CF 14 4XN

Aims: Almost all the evidence on breast feeding and cognitive development comes from recent studies in which the mothers who breat feed are likely to have greater than average concerns in health and in social and educational matters. This Caerphilly cohort consists of men born in a relatively deprived area, between 1920 and 1938, when breast-feeding was usual. Neither social nor educational factors are likely to have played much part in a decision by a mother to bottle feed her infant. Moreover, psychological and other influences of the mother upon her child are likely to be trivial 60 and more years later.

Methods: Men enlisted into the Caerphilly vascular disease cohort study were asked to obtain from their mothers their birth weight and details of their feeding as infants. Fifteen years later, when aged 60-74 years, the men did a number of cognitive function tests. Relationships between having been breast or bottle fed and cognitive function were examined, adjusting for possible social and educational confounding factors

Results: $1505(60 \%)$ of the 2512 men in the cohort obtained information on their feeding as infants. $344(23 \%)$ had not been breast fed, and of the 1161 (77\%) who had been breast fed 686 knew the duration. Data on cognitive function were obtained for just over half of these men. Men whose birth weight had been above the median showed small, but non-significant differences in favour of having been breast-fed. Below the median birth weight, men who had been breast fed showed large and significant differences in the test of reasoning and in the test of word power (NART), compared with the men who had been bottle fed. Two SD below the mean birth weight breast-feeding was associated with an excess of 6 points on the NART (about $70 \%$ of a SD), while two SD above the mean birth weight, the gain was only 1 NART point (about 10\% of a SD).

Conclusions: Breast-feeding is associated with better cognitive function in later adult life in men with low birth weight. 
Abstract $\mathrm{G} 18$

\begin{tabular}{lll}
\hline Subject category & Mean cost in Sterling** & Survival time in months** \\
\hline Terminally ill $n=6$ & $51,013(11,767-99,515)$ & $1.56(0.5-4.8)$ \\
Stable on home PN $n=21$ & $254,999(184,527-354,013)$ & $28.3(24.5-29.6)$ \\
In need of SBTx $n=23$ & $197,555(159,534-231,658)$ & $21.2(16.6-26.3)$ \\
a) SBT $\mathrm{n}=13$ & $259,549(211,269-318,455)$ & $21.1(15.0-27.6)$ \\
b) Treatment costs in absence of SBTx* & $276,364(225,052-345,399)$ & $15.8(13.3-20.2)$
\end{tabular}

*Shadow costs and survival using the prognostic model; ** $95 \%$ confidence limits.

\section{G18 COST EFFECTIVENESS OF SMALL BOWEL TRANSPLANTATION FOR PAEDIATRIC PATIENTS}

S.V. Beath, D.A. Kelly, L. Longworth', D. Sandhu, T. Young', H. Mistry', J. Ratcliffe', S.M. Protheroe', P.J. McKiernan, J. deVille de Goyet, M. Buxton'. The Liver Unit, and 'Gastroenterology Dept, Birmingham Children's Hospital; 'The Health Economics Research Group, The University of Brunel, UK

Chronic intestinal failure (IF) may be treated with long term parenteral nutrition (PN) or small bowel transplantation (SBTx). Both treatments are costly and have the potential to cause life-threatening complications especially in children.

Objectives: To evaluate (1) cost of treating a cohort of 50 children with IF who were referred for possible SBTx at our hospital 1997-2001, (2) the cost effectiveness of SBTx in a subgroup who fulfilled clinical criteria for transplantation.

Subjects: Children with either liver dysfunction (74\%), thrombosis of the vena cava $(18 \%)$ or both $(8 \%)$. All were assessed clinically and categorised as: i) in need of intestinal transplantation because of life threatening complications related to $P N(n=23)$, ii) not in need of SBTx $(\mathrm{n}=21)$, and iii) terminally ill from complications of long term PN but unable to survive transplant operation $(n=6)$.

Methods: The overall cost of treating IF was derived from major resource use data (in-patient stays, out-patient visits, intravenous feeding solutions, blood products, drug treatment, and theatre sessions) prospectively entered on a database for all patients who were followed up for 30 months (or as long as they survived). Cost effectiveness of SBT $x$ was measured by comparing the outcome of transplanted patients $(n=13)$ with their expected experience in the absence of transplantation using a prognostic model based on serum bilirubin and prothrombin times.

Results: Survival and costs over 30 months for children with IF varied greatly. See table. The terminally ill group incurred a relatively small cost because they did not survive long. The cost of supporting children with IF is higher than previously reported and is likely to be due to all the costs being comprehensively identified. The analysis showed that SBTx conferred a modest survival benefit and was a cost effective treatment but only for children at risk of fatal complications secondary to $\mathrm{PN}$.

Conclusion: SBTx is cost effective but the overall costs of treating IF with or without transplantation, argue for a nationally coordinated service.

\section{G19 THE BPSU STUDY OF BILIARY ATRESIA: OUTCOME AFTER 8 YEARS}

P.J. McKiernan, A.J. Baker', G. Mieli-Vergani', D.A. Kelly. Liver Unit, The Children's Hospital NHS Trust, Birmingham; 'Paediatric Liver Unit, King's College Hospital, London

All cases of biliary atresia in the British Isles diagnosed between March 1993 and February 1995 have been followed prospectively. Analysis after a median follow up of 3 years showed that outcome was better, with higher overall survival and survival without liver transplantation, in surgical centres managing $>5$ cases yearly.'

Aim: To describe the current outcome of a national cohort of children with biliary atresia.

Subjects: 93 children with biliary atresia diagnosed between March 1993 and February 1995. Median age at last follow up was 8 years (range $0.25-10$ )

Results: 15 children (16\%) have died. 10 died following unsuccessful Kasai portoenterostomy and 4 following liver transplantation. $41(44 \%)$ have undergone liver transplantation at median age 1 year $(0.5-7)$, with $90 \%$ survival after median follow up of 7 years (0-9 years). All 41 children with failed Kasai have died or undergone liver transplantation at median age of 0.8 years $(0.25-6.5)$. Where the Kasai was successful $41 / 50$ (82\%) are alive without liver transplantation. 8 year actuarial survival without liver transplantation was $44 \%$ overall, and was more likely in children managed in centres treating $>5$ cases yearly, $(56 \%$ v $27 \%, p=0.004)$.

Conclusions: In biliary atresia: (1). If the Kasai portoenterostomy is successful few children will need liver transplantation before 8 years old. (2) Liver transplantation is very successful if the Kasai portoenterostomy fails. (3) Children should be managed in experienced centres.

1. McKiernan PJ, et al. Lancet 2000;355:25-9.

\section{G20 IMPROVED QUALITY OF LIFE IN CHILDREN WITH ACUTE CROHN'S DISEASE AFTER TREATMENT WITH EXCLUSIVE ENTERAL NUTRITION: USE OF IMPACT II QUESTIONNAIRE}

N.A. Afzal', H.J. Loonen² F. Arnaud-Battandier ${ }^{3}$ S. Davies' S. Murch', B. Derkx', R. Heuschkel', J.M. Fell ${ }^{4}$. 'Royal Free Hospital, London; ${ }^{2} E m m a$ Children's Hospital, The Netherlands; ${ }^{3}$ Nestec, Clinical Nutrition; ${ }^{4}$ Chelsea and Westminster Hospital, London

Aim: Optimal medical treatment with improvement in quality of life (QOL) is essential for management of children with chronic disorders such as Crohn's disease. Exclusive enteral nutrition remains an important but under-prescribed first line treatment for acute Crohn's disease in children. Our aim was to prospectively assess the change in QOL following this treatment.

Methods: We recruited 26 consecutive children (18 males) aged 11-16 years with active Crohn's disease (PCDAl > 20) from two centres with expertise with this therapy. They were treated with a new exclusive polymeric feed for 8 weeks. We used IMPACT II, an age and disease specific questionnaire for children with Crohn's disease, to assess their QOL in response to therapy. All children had endoscopic and clinical disease activity assessed at diagnosis and after 8 weeks.

Results: $23 / 26$ children achieved a clinical remission at 8 weeks. There was a significant improvement in the total quality of life score after treatment $(p<0.01)$. However, there was only a significant improvement in $4 / 6$ of the questionnaire domains (IBD symptoms, systemic symptoms, emotional and social functioning) ( $p<0.01)$. A positive correlation between the PCDAl and total QOL score was detected at both time points (Pearson's correlation, $r=-0.6, p<0.01$ ), whilst there was also a significant correlation between an individual's improvement in QOL score and the change in their PCDAl (Pearson's correlation, $r=-0.67, p<0.011$.

Conclusions: This study further validates the use of the IMPACT II questionnaire for the assessment of $\mathrm{QOL}$ in children with Crohn's disease. We have been able to clearly document for the first time, that clinical disease remission, induced by exclusive enteral nutrition, is associated with an improvement in QOL. Although some feel that the use of exclusive nutritional therapy disregards a child's quality of life, this study clearly demonstrates not only its ability to improve clinical disease activity, but also it's significant improvement on their quality of life.

\section{G21 MATERNAL NUTRIENT RESTRICTION BETWEEN EARLY TO MID GESTATION REDUCES MITOCHONDRIAL CYTOCHROME C ABUNDANCE IN THE KIDNEY OF THE RESULTING OFFSPRING AT TWO YEARS OF AGE}

D. Yakubu, G. Gopalakrishnan, A. Mostyn, S.M. Rhind', C.E. Kyle' A.N. Brooks', M.T. Rae', T. Stephenson, M.E. Symonds. Academic Division of Child Health, School of Human Development, Queen's Medical Centre, University Hospital, Nottingham NG7 2UH; 'Macaulay Land Use Research Institute, Aberdeen; ${ }^{2}$ Astrazeneca, Alderly Park, Cheshire

Aims: Maternal nutrient restriction over the period of rapid placental growth (i.e. 30-80 days), followed by adequate nutrition up to term, 
results in a longer fetus with a disproportionately larger placenta. At term, these lambs have larger kidneys which exhibit an increased abundance of glucocorticoid receptor mRNA. Then at six months of age, lambs born to previously nutrient restricted (NR) ewes exhibit lower resting blood pressure, but show an increased pressor response to noradrenaline. The aim of this study was to determine the consequences of maternal nutrient restriction between early to mid gestation on kidney size and mitochondrial function in adulthood.

Methods: Eighteen singleton-male-bearing Scottish Blackface ewes of similar live weight and body condition were individually housed from day of mating. All ewes were randomly assigned, within live weight and body condition class, to be fed either 50 (nutrient restricted; NR) or 100 (controls; C) \% of total metabolisable energy requirements (ME) up to 95 days of gestation. All ewes then consumed $100 \%$ of ME requirements up to term. From birth until 2 years of age all rams were treated as one flock and conventionally managed. Kidneys were sampled at 2 years of age. Mitochondrial fractions were prepared and cytochrome $c$ abundance determined. Results are given as means with their standard errors in arbitrary units and are expressed as a percentage of a reference sample present on all gels.

Results: There was no difference in ram body weight at birth or two years of age, nor in kidney weight and shape. However, kidneys sampled from NR rams had a significantly reduced abundance of cytochrome $c$ compared with $C$ ewes (C $26.2 \pm 2.2$; NR $19.6 \pm 1.3$ $(\mathrm{p}<0.01))$.

Conclusion: A reduction in mitochondrial cytochrome $c$ within the kidney of NR offspring may be indicative of compromised function that could increase predisposal to adverse blood pressure control in later life.

\section{G22 HIGH PREVALENCE OF COELIAC DISEASE IN YOUNG HEALTHCARE PROFESSIONALS.}

S. El-Hadi, E. Lewis' ${ }^{1}$ A. Adisesh', M. Moody², R. Fyfield², G. Thomas ${ }^{3}$, P.E. Williams'2, D. Tuthill, H.R. Jenkins. Departments of Child Health, 'Occupational Health, ${ }^{2}$ Immunology, and ${ }^{3}$ Gastroenterology, University Hospital of Wales, Cardiff CF14 4XW

Previous reports suggested that Coeliac Disease $(C D)$ in children was declining in the UK. However a recent study in children has contradicted this.' The current major British paediatric textbook states the prevalence of $C D$ is 1 in $2-6000^{(2)}$, but this may well be an underestimate.

Aim: To prospectively assess the prevalence of $C D$ amongst young healthcare students.

Methods: All new healthcare students attending for hepatitis B serological testing were offered screening for $C D$. Full blood count analysis was performed and serum was assayed for total $\lg \mathrm{A}$, anti-issue transglutaminase (TTG-Orgentec ELISA) and anti-gliadin antibodies (AGA-Pharmacia Cap). For those in whom IgA deficiency was identified IgG AGA were measured. Students with either raised positive AGA or TTG levels had repeat assays performed in addition to anti-endomysial antibody (AEA) estimation. Those with positive results were referred for assessment, counselling and endoscopy.

Results: 1000 samples were analysed over 18 months. Two students were anaemic. No AGA levels were raised to diagnostic values. Two repeated raised TTG values (>15 units/ $\mathrm{ml}$ ) were found in 17 subjects of whom 6 had positive AEA. Fifteen students have undergone endoscopy of whom 6 had positive biopsies for CD. Two students declined endoscopy.

Conclusion: The minimum prevalence of $C D$ in young healthcare students in our study is 1:166.

1.Tuthill DP, Hawkes N, Jenkins $H$. The rise of childhood coeliac disease following serological testing. Arch Dis Child 1999;80(suppl 1):A22.

2.Textbook of Paediatrics. Forfar and Arneil, 5th Edition. Churchill Livingstone Press, 2000:440.

\section{G23 FLY CONTROL AND PROVISION OF PIT LATRINES DOES NOT DELAY ACQUISITION OF HELICOBACTER PYLORI IN GAMBIAN VILLAGES}

S.J. Allen, J.E. Thomas, N.D.E. Alexander, R.L. Bailey, S.W. Lindsay, P.M. Emerson. Medical Research Council Laboratories, Fajara, PO Box 273, Banjul, The Gambia

Although one of the commonest infections of man, how $H$ pylori is transmitted is unknown. Clustering of infection within families and institutions suggests that close contact, possibly faecal-oral is required, but the organism is difficult to culture from stools. Flies have been suggested as a possible vector. In developing countries acquisition of $H$. pylori normally occurs during infancy. During a study of the effect of fly control and provision of pit latrines on trachoma in Gambian villages, we assessed the impact of these interventions on $H$ pylori infection.

Aims: To assess whether insecticide spraying to control flies or provision of pit latrines delayed acquisition of $H$ pylori in young children living in villages in The Gambia.

Methods: ${ }^{13} \mathrm{C}$ urea breath tests (UBT) were performed at baseline in children aged 6-18 months from 18 clusters of villages assigned randomly to either spray, latrines or control and repeated 6 months later.

Results: At baseline, the median (IQR) age of children was 11.0 (8.5-14.3) months and $135 / 216(62.5 \%)$ had a positive UBT. UBT positivity and age were similar across the study groups. The frequency of positive UBTs increased with age from $32 \%$ at 6 months to $91 \%$ at 12 months. Fly populations were reduced by about $80 \%$ by spraying and $30 \%$ by latrine provision. The number (\%) of children UBT negative at baseline and positive at follow-up was 16/21 (76.2) in the insecticide group, 15/26 (57.7) in the latrine group and 23/31 (74.2) in the controls $(p=0.29)$. The number of children UBT positive at baseline and negative at follow-up was $8 / 33$ (24.2), 12/50 (24.0), $8 / 48$ (16.7) in the respective groups ( $p=0.61$ ).

Conclusions: The lack of effect of these interventions in reducing infection with $H$ pylori argues against flies being a major route of transmission and provision of latrines as a control measure in this setting.

\section{G24 PROSPECTIVE AUDIT OF A NEW PAEDIATRIC LIVER TRANSPLANT PROGRAMME}

P. McClean, S.M. Davison, M. O'Meara, S. Whiteley, J. Luntley, K.R. Prasad, M.D. Stringer. Children's Liver \& Gl unit, St James's University Hospital, Leeds, UK

Establishing a new specialist service compassing high risk patients and procedures involves a learning curve. Can morbidity and mortality be minimised in the early years of a new paediatric liver transplant service?

Methods: A centre with a robust adult liver transplant service initiated a paediatric programme in November 2000 after an 18 month period of intensive preparation which included: appointing and training a multidisciplinary team; establishing appropriate facilities; and developing clinical guidelines. The outcome of all liver transplants was audited prospectively.

Results: Between November 2000 and October 2002, 30 orthotopic liver transplants were performed in 28 children $(12$ male, median age 2.5 y [19d-15y]). Nine (32\%) children were transplanted for acute liver failure (ALF), the remainder had end-stage chronic liver disease. Eighteen split-liver, 8 whole and 4 reduced grafts were transplanted. Immunosuppression was with Tacrolimus and prednisolone.

Twenty-five children $(89 \%)$ are alive at a median follow up of 13 months. Three children with ALF died soon after transplantation despite good graft function (cerebral oedema, intraventricular haemorrhage, viral myocarditis). Two children were successfully retransplanted for hepatic artery thrombosis and primary non-function. Acute cellular rejection occurred in $44 \%$ of cases and 2 children are responding to treatment of chronic rejection. Other complications comprised acute renal failure (3), hepatic artery thrombosis (1), hepatic artery stenosis (1), late portal vein stenosis/thrombosis (3), and CMV pneumonitis (1): all were treated successfully. One child, transplanted for ALF, has aplastic anaemia and another has idiopathic primary pulmonary hypertension.

Conclusions: Despite a greater proportion of high risk cases these results are comparable to those from established centres. With careful planning a new paediatric liver transplant service can achieve good outcomes.

\section{G25 CAN THE NEED FOR AZATHIOPRINE BE PREDICTED AT THE TIME OF INITIAL PRESENTATION WITH IBD?}

H. Mossop, P. Davies, M.S. Murphy. Institute of Child Health, University of Birmingham \& Department of Paediatric Gastroenterology, Birmingham Children's Hospital

Introduction: AZA is an effective treatment for IBD, but is usually reserved for troublesome cases. However, this 'wait-and-see' policy could result in avoidable illness and steroid toxicity. There are no published studies on predicting the need for AZA. 
Aim: to identify disease characteristics that would predict the need for AZA at initial presentation.

Methods: The records of 156 cases $(93 \mathrm{CD}, 47$ UC, $16 \mathrm{IC}$ ) were reviewed. In these patients AZA was reserved steroid resistance/ dependence and frequent relapse. 30 variables were evaluated including symptoms, BMI and Height $z$ scores, disease distribution/ extent, colitis severity, blood indices, and intensity of first treatment (see below). The variables were examined by stepwise logistic regression.

Results: Overall AZA was eventually prescribed for $36 \%$ with $C D$, $40 \%$ with UC and $38 \%$ with IC. Three presenting variables had a significant association with AZA usage: oesophageal $C D$, severe colitis, and the use of IV steroids. See table.

\begin{tabular}{|c|c|c|c|}
\hline \multicolumn{4}{|l|}{ Abstract G25 } \\
\hline & AZA\% & $p$ value & $\begin{array}{l}\text { Odds Ratio } \\
\text { (95\%Cl) }\end{array}$ \\
\hline \multicolumn{4}{|l|}{ Crohn's disease } \\
\hline Oesophageal disease & $82 \%$ & 0.004 & $10.3(2.1-51)$ \\
\hline Severe colitis & $50 \%$ & 0.05 & $2.7(1-7.5)$ \\
\hline \multicolumn{4}{|l|}{ Treatment level } \\
\hline 1 No steroids, no elemental diet & $20 \%$ & & \\
\hline 2 Oral steroids or elemental diet & 39.45 & 0.12 & $2.6(0.8-8.6)$ \\
\hline 3 Intravenous steroids & $75 \%$ & 0.05 & $12(1-148.3)$ \\
\hline \multicolumn{4}{|c|}{ Ulcerative colitis } \\
\hline Severe colitis & $57 \%$ & 0.02 & $4.7(1.3-16.7)$ \\
\hline \multicolumn{4}{|l|}{ Treatment level } \\
\hline 1 No steroids & $16.7 \%$ & & \\
\hline 2 Oral steroids & $45.2 \%$ & 0.1 & $4.1(0.8-22)$ \\
\hline 3 Intravenous steroids & $75 \%$ & 0.05 & $15(1.0-229)$ \\
\hline
\end{tabular}

Conclusion: Those requiring IV steroids at presentation or with oesophageal CD usually require AZA. In 'severe colitis' AZA is more often required, but still about $40-50 \%$ avoid it. Otherwise the need for AZA seems unpredictable.

\section{G26 USE OF METHOTREXATE FOR INDUCTION OF REMISSION IN CROHN'S DISEASE: A RETROSPECTIVE COHORT STUDY}

L. Pieterse', P. Rogers', D. Hoole'2, P.M. Gillett', D.C. Wilson', 3. ' Dept of Paediatric Gastroenterology and Nutrition, and 'Dept of Pharmacy, RHSC, Edinburgh; ${ }^{3}$ Department of Child Life and Health, University of Edinburgh

Introduction and aim: There is good evidence from studies in adults that methotrexate (MTX) is useful in the induction and maintenance of remission in patients with Crohn's Disease (CD) refractory to other immunomodulatory treatment. MTX has been shown to induce remission in some paediatric patients with Crohn's disease. However the reported data on this is limited to a small North American case series. We wished to review our population of children treated with MTX, regarding both induction of remission and side effects.

Methods: A retrospective cohort study of all 115 children $\mid<18$ years) with inflammatory bowel disease referred to, and treated in the regional centre for SE Scotland from 1/8/97 to 1/11/02. Of 75 patients with $C D, 47$ received azathioprine. Eleven patients ( 7 boys) with $C D$ diagnosed at median age of 10 years (range 7-17) received subcutaneous MTX weekly for sixteen weeks. It was instituted for induction of remission in children with relapsing disease and: failure to respond to azathioprine $(n=9)$, adverse reaction to azathioprine $(n=1)$, or improved adherence to treatment $(n=1)$. Outcome measures of clinical remission (defined as clinical improvement in all symptoms) and side effects were followed.

Results: Remission occurred in 10 patients $(91 \%)$, with median time to improvement of 8 weeks (range 5-16). MTX was well tolerated; two patients had mild elevation of ALT only and one had minor irritation at the injection site.

Conclusions: Subcutaneous MTX appears to be safe and effective in inducing remission in children who have failed to respond to first line immunomodulatory treatments with azathioprine.

\section{G27 DETRIMENTAL EFFECTS OF CONSUMERISM IN MEDICINE: LESSONS FROM CHILDREN WITH FUNCTIONAL ABDOMINAL PAIN}

K.J. Lindley, D. Glaser, P.J. Milla. Institute of Child Health, University College London and Great Ormond Street Hospital for Children NHS Trust, London, UK

Functional abdominal pain (FAP) in childhood as defined by the Rome II criteria is commonly associated with unrecognised psychological factors and a degree of parent-child enmeshment. We hypothesised that the increasingly consumeristic approach to medicine advocated by governments and medical professional bodies alike might be counterproductive in enmeshed families who lack insight into the origins of their child's FAP. 23 consecutive referrals $111 \mathrm{M}, 12 \mathrm{~F}$ median age 14 years) of children with FAP to a single gastroenterologist at a tertiary referral centre were studied retrospectively. All had been investigated according to standard clinical service guidelines and a positive diagnosis of FAP made. Predictors of outcome were analysed using Fisher's exact test.

$15 / 23$ had already had $>2$ Consultant opinions and 14/15 were dissatisfied with such opinions. 9/23 were frankly hostile towards the medical profession at first consultation in GOSH. 12/23 had complained about some aspect of their child's care ( $9 / 12$ at GOSH) and $8 / 12$ complaints were overt attempts to manipulate some facet of their child's care (for example further referral or inappropriate investigation). Investigation via the formal Hospital complaints procedure did not find the physician at fault in any instance. In $12 / 13$ of the families who accepted psychological referral there was evidence of family conflict/dysfunction and poor insight into the child's illness. Poor outcome (defined as pain lasting >12 months and failure to return to normal levels of functioning) was associated with lack of insight into psychosocial influences upon the illness $(p<0.001$, rr $7.49)$, refusal to engage with psychological services $(p<0.05, \mathrm{rr}$ $4.55)$, involvement of $>3$ consultants $(p<0.05, \mathrm{rr} 7.00)$ and lodging of a manipulative complaint ( $\mathrm{p}<0.05$, $\mathrm{rr} 3.25$ ).

Healthcare consumerism in families lacking insight is deleterious for the child with FAP. Robust systems are necessary to protect the child (and their physician) from the consequences of consumerism in medicine.

\section{G28 EVIDENCE OF CFTR DYSFUNCTION IN CHILDREN WITH RECURRENT PANCREATITIS}

M. Corpino, M.A. Thompson, P.J. Milla, A. Jaffe, K.J. Lindley. Institute of Child Health, and Great Ormond Street Hospital for Children NHS Trust, and Department of Paediatric Gastroenterology, Royal Free Hospital, London, UK

There is increasing recognition that dysfunction of the cystic fibrosis transmembrane regulator (CFTR) molecule is associated with clinical disorders distinct from classical cystic fibrosis (CF). Idiopathic chronic pancreatitis (ICP) has been associated in adults and children with mutations of CFTR. We studied 12 children referred consecutively to GOSH with acute pancreatitis. Gene mutations in ABCC8 (CFTR) associated with cystic fibrosis (31 mutations) were sought as was the status of the intron 8 poly T region. CFTR function was investigated using the sweat test and measurement of nasal epithelial potentential difference (basal, post amiloride and post stimulation of CFTR regulated chloride currents $[\triangle \mathrm{PDCl}])$. 1/12 patients was heterozygous for $\Delta F 508$. No other mutations in CFTR were found. All had normal sweat tests. 11 patients tolerated measurement of nasalPD. Basal nasap pd and $\triangle P$ Damiloride were comparible in controls and children with pancreatitis (Basal pd (mean \pm sem): control $12.2 \pm 1.6, \Delta \mathrm{F} 508$ homozygotes $33.9 \pm 2.4$, pancreatitis $14.5 \pm 1.6 ; \Delta$ PDamiloride control $4.8 \pm 1.2, \Delta \mathrm{F} 508$ homozygotes $17.1 \pm 1.7$, pancreatitis $6.0 \pm$ 1.25). $\triangle \mathrm{PDCl}$ was significantly lower in children with pancreatitis than in controls, but higher than that seen in children with classical cystic fibrosis (controls $23.3 \pm 2.0, \Delta \mathrm{F} 5080.8 \pm 1.4$, pancreatitis $12.6 \pm$ $2.0 \mathrm{P}<0.005$ pancreatitis $v$ controls, $\mathrm{p}<0.001 \mathrm{CF} v$ controls $) .8 / 11$ children with pancreatits had $\triangle \mathrm{PDCl}$ values within the range seen in $\triangle$ F508 CFTR homozygotes. All patients were nergative for gene mutations in PRSS1 associated with hereditary pancreatitis.

We provide evidence of CFTR dysfunction in 8/11 children with recurrent acute pancreatitis/ICP despite an absence of association with common cystic fibrosis associated gene mutations. CFTR dysfunction is a risk factor for pancreatitis which should be included within the spectrum of CFTR related disease. 


\section{G29 ENDOSCOPIC GASTROPLICATION FOR THE TREATMENT OF PAEDIATRIC GASTRO-OESOPHAGEAL REFLUX DISEASE}

M.A. Thomson', N. Afsal', R. D'Souza², A. Fritscher-Ravens², P. Swain². 'Centre for Paediatric Gastroenterology, Royal Free Hospital, London; ${ }^{2}$ Royal London Hospital, London

Background: A method has been developed whereby sutures can be placed via an endoscope just below the oesophago-gastric junction (OGJ) whose purpose is to improve the function of the OGJ and thereby prevent gastro-oesophageal reflux. We describe our experience of the use of the BARD Endocinch $\odot$ device for the treatment of GORD in children and adolescents.

Methods: 20 patients ( 3 neurologically compromised, 8 male, median (range) age 12.8 years (6.1-17.7), median (range) weight $46 \mathrm{~kg}(16.5-75))$ with symptoms of GORD dependent on PPIs for $>12$ months, or refractory to PPls underwent endoscopic gastroplication (EG) under GA, following informed patient/parental consent, with median 8 month follow up. Those not considered were $>18$ years, or with dysphagia, obesity $(B M I)>99^{\text {th }}$ centile, previous upper intestinal surgery, or hiatus hernia $>2 \mathrm{cms}$. Pre-procedure assessment included upper $\mathrm{Gl}$ endoscopy, oesophageal manometry (in 4), liquid and solid phase gastric scintiscan, 24 hour oesophageal pH, symptom scoring, and completed reflux quality of life (QOLRAD) and gastrointestinal rating score (GSRS) questionnaire (except if neurological compromise). Post-procedure symptomatology, $Q O L$ and adverse events were assessed at 1, 3, 6, and 12 months. Repeat 24 hour $\mathrm{pH}$ was performed at 2 months (16 patients).

Results: Median duration for 3 plications ( 3 pairs of sutures) was 65 (55-127) minutes. Median heartburn symptom score (daily heartburn frequency $x$ severity $(0-10)$ ) was 24 pre-EG, and 0 at six weeks and 6 months. Total QOLRAD (best 175) increased from a median of $83(70-142)$ to $157(93-175) \quad(p<0.001)$, and with all subparameters and was sustained. Median RI improved from $14.8 \%$ $(0.9-67.9)$ to $2.7 \%(1.0-6.9)(\mathrm{p}<0.001)$. All other $\mathrm{pH}$ parameters also improved significantly. Median $\mathrm{pH}$ Demeester score from 67.1 $(6.1-68.3)$ to $11.6(5.0-31.2)(p<0.001)$. 18/20 did not require any further PPI use at any stage (median PPI dose pre-EG was 0.89 (0.3$2.42) \mathrm{mg} / \mathrm{kg} /$ day). One patient had localised gastric bleeding requiring red cell transfusion which settled spontaneously and no other adverse events were seen.

Conclusions: This is the first report of paediatric experience with an endoscopic anti-reflux procedure and this shows it to be a safe and effective method of managing GORD in the paediatric age group. 